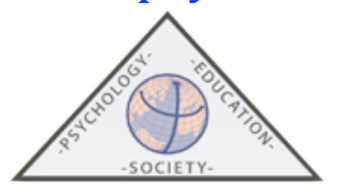

\title{
Teacher Professional Development in Singapore: Depicting the Landscape
}

\author{
Alfredo BAUTISTA, Joanne WONG, \& Saravanan GOPINATHAN \\ Nanyang Technological University, National Institute of Education (Singapore)
}

\section{(Received on January 20, 2015; Accepted on August 31, 2015)}

\begin{abstract}
ABTRACT: This article depicts the landscape of teacher professional development (PD) in Singapore, one of the world's top-performing countries in education. We provide an overview of the resources available to the approximately 30,000 teachers within the 350 primary and secondary schools run by the Ministry of Education (MOE). We focus on the three main PD providers: the National Institute of Education, the Academy of Singapore Teachers and six Centers of Excellence, and schools themselves. Guided by the "Teacher Growth Model," these providers aim at making PD coherent with teachers' interests, the needs of schools, and the national curriculum. Teachers in Singapore are given the exceptionally high allotment of 100 voluntary hours of PD per year. There are multiple types of activities teachers can engage in, ranging from formal/structured courses and programs to more informal/reform-based initiatives (action research, lesson study). Teachers with different levels of expertise and career paths have access to different PD opportunities. Most PD is subject-specific and provides teachers with opportunities for networked learning, collegial sharing, and collaboration. In fact, all MOE schools have been recently mandated to become Professional Learning Communities (PLC). We conclude that this comprehensive set of PD resources, considered as a whole, presents the features of "high-quality" PD described in the international literature. However, we suggest that more research is needed to examine the extent to which such an ambitious PD model is enhancing teachers' knowledge and pedagogies, and ultimately students' learning.
\end{abstract}

Keywords: teacher professional development, Singapore, in-service teachers, teacher learning

Acknowledgements: This study was funded by the Education Research Funding Programme, National Institute of Education (NIE), Nanyang Technological University, Singapore, project no. OER 02/14 AA. The views expressed in this paper are the author's and do not necessarily represent the views of NIE.

Correspondence: Alfredo Bautista, Research Scientist \& Lecturer. Nanyang Technological University National Institute of Education. Education \& Cognitive Development Lab. 1 Nanyang Walk. NIE5-B3-16. Singapore [637616]. Phone: (+65) 6219 6256. Fax: (+65) 6896 9845. E-mail: Alfredo.Bautista@nie.edu.sg

\section{How to cite this article?}

Bautista, A., Wong, J., \& Gopinathan, S. (2015). Teacher professional development in Singapore: Depicting the landscape. Psychology, Society and Education, 7(3), 311-326. 


\section{Introduction}

Located at the core of Southeast Asia, the small city-state of Singapore is a story of rapid transformation and success. Upon its independence from Malaysia in 1965, this island country only took three decades to evolve from a sleepy fishing village into a major commercial hub, boasting one of the largest financial centers in the world. Immediately after independence, the one-party government (still in power today) adopted the English language as its main medium of communication, not only for business but also in education. Living in a country with no natural resources, Singaporeans widely believe that the survival of their nation is hinged on the development of "human capital" (Gopinathan, 2012). This belief became one of the driving forces behind Singapore's consistent efforts in enhancing the quality of its education system, and in particular -as shown in this article- of the preparation and professional development opportunities offered to its teaching force (Ellis, 2014).

Singapore is currently considered to be one of the world's top-performing countries in education, based on indicators such as students' test scores in international comparisons, graduation rates, and percentage of students pursuing higher education (World Economic Forum's Global Competitiveness Report 20142015, see Schwab, 2015). Year after year Singaporean students consistently achieve top scores in mathematics, science, and literacy in cross-national assessments such the Programme for International Student Assessment (PISA), Trends in International Mathematics and Science Study (TIMSS), and Progress in International Reading Literacy Study (PIRLS).

Recent research indicates that the success of Singapore's education system is due to multiple factors at three independent levels: the macro level (socio-cultural, economic-political factors); the organizational level (quality of schools, teachers, curriculum, etc.); and the family level (parenting and socialization) (Dimmock \& Tan, 2013; Hairon \& Dimmock, 2011; Tan \& Dimmock, 2014). Without a doubt, the organizational level has sparked the most interest and curiosity amongst educators, researchers, and policymakers around the world in recent years. The Singapore Ministry of Education (MOE) has carefully designed its education system by examining "best practices" of other countries (e.g., successful schools, education policies, curriculum, pre-service education, professional and leadership development programs), which has contributed to radically transform the educational landscape in a short time-span (Gopinathan, 2012). Given its proven success, we think other countries might be interested in looking at what Singapore is currently doing regarding education matters.

This article focuses on teacher Professional Development (PD), which can be thought of as a specific factor within the organizational level described above. Today, Singapore offers a wide variety of PD opportunities for teachers of all grade levels and content areas, from early childhood to higher education. In this paper, we provide a brief overview of the resources available to the approximately 30,000 teachers who 
work in the 350 primary and secondary schools run by the MOE ${ }^{1}$. We show that teacher PD in this country (a) is subject-matter specific and connected to classroom practice; (b) is intensive and ongoing; (c) provides teachers with opportunities for active learning; (d) promotes collective participation amongst teachers both across and within schools; and (e) is coherent with teachers' needs and interests, and aligned with school and national priorities. On the basis of these general features, we argue that the Singapore's teacher PD model presents the features of "high-quality" PD described in the international literature (e.g., Avalos, 2011; Bautista, Cañadas, Brizuela, \& Schliemann, 2015; Borko, 2004; Darling-Hammond \& McLaughlin, 2011; Desimone, 2009). Nevertheless, because we acknowledge the complexity of reasons that explain Singapore's success in education (Dimmock \& Tan, 2013; Hairon \& Dimmock, 2011; Tan \& Dimmock, 2014), we by no means intend to establish simple causal relationships between the quality and/or quantity of the PD opportunities offered to teachers in Singapore and the high achievement of its students. As discussed in the Introduction to this monograph (Bautista \& OrtegaRuíz, 2015), the influence of teacher PD needs to be analyzed from a systemic and complex perspective.

\section{General Features of Teacher Professional Development (PD) in Singapore}

Teaching is a highly regarded and respected profession in Singapore. Its citizens understand that teachers play a vital role in the nation's development and progress. Thus, the candidates recruited to become future teachers are chosen very carefully.

The MOE has developed varied strategies for the recruitment, compensation, and induction of primary and secondary school teachers (Darling-Hammond, 2010). Candidates accepted into teacher preparation programs are selected from the highest achieving students of each cohort of graduating students (within the top one third). The majority of candidates have taken the Cambridge Advanced Level examinations (also known as " $A$ " Levels), which is currently the most challenging assessment available to Singaporean students, scoring at least in the middle to top percentile. Other candidates commonly recruited to become teachers are university degree holders. All candidates need to go through a thorough application process that typically includes a panel interview (focusing not only on their intellectual capacities but also on their interests and personal qualities), an assessment of their commitment to the teaching profession, service to diverse student populations, reviews of academic records, and past contributions to their alma mater and community. After this comprehensive process, which reflects how highly regarded the teaching profession is in Singapore, only about one eighth of the candidates are accepted (Darling-Hammond, 2010). Once they start with their teacher education programs,

\footnotetext{
${ }^{1}$ We focus on teachers from both government-run and government-aided primary and secondary schools. Singapore also has a few independent, specialized, and independent/specialized schools (15 in total), as well as a number of private schools offering foreign education systems (approximately 40). The PD opportunities offered to teachers from these other schools might differ from the ones described here.
} 
student teachers receive a stipend equivalent to $60 \%$ of an in-service teacher's salary during the entire duration of their programs (which ranges from $3 \frac{1}{2}$ to 6 years). After program completion, teachers are bonded to teaching for a certain number of years, depending on the duration of their initial preparation program.

With the initiative "Thinking Schools, Learning Nation" (Goh, 1997), Singapore started to pay special attention to the continuing professional development (PD) offered to its teaching force. This initiative moved away from the traditional conception of the teacher as a technician to conceiving teachers as reflective professionals (Deng, Gopinathan, \& Lee, 2013). Since then, PD has been considered a cornerstone to the improvement of teachers' capacity to teach to a higher standard. Subsequent initiatives launched by MOE, such as "Teach Less, Learn More" (MOE, 2005) or the current professional development model, called "Teacher Growth Model" (MOE, 2012), have further emphasized the key role that teacher PD plays in the improvement of education. Currently, there is agreement amongst policy makers, researchers, and teacher educators that major curriculum and pedagogic reform agendas require innovation in $\mathrm{PD}$, and that capacity building is essential if reform is to succeed.

The "Teacher Growth Model" encourages teachers to further their learning through a variety of formats and platforms, including face-to-face and online courses, workshops, and postgraduate programs (e.g., Masters and PhDs), professional conferences, conventions, and symposiums, action-research, mentoring and coaching, and school-university partnerships (MOE, 2012). The different initiatives range from traditional forms of PD (such as formal courses) to reform-based initiatives (such as informal sharing sessions, action research, or peer observations). Teachers are also encouraged to use part of their PD time to learn about topics not directly related to teaching, for example counseling, multicultural education, personal well-being, or social skills (Tripp, 2004). The rationale is that, through these types of educational experiences, teachers will become better equipped to meet the requirements and challenges of education in the $21^{\text {st }}$ century (MOE, 2012).

Teachers can undertake up to 100 hours of voluntary PD activities per year. Completing these 100 hours is an entitlement (optional), not a requirement, although most teachers take advantage of them (Wong, 2013). Every year, at least one member of the school's senior management (which generally consists of the principal, viceprincipal, heads of department, level heads and subject heads, and also staff developers in some schools) discusses with the teachers how to plan their yearly PD agenda, in response to the motivations and interests of the teacher, the needs of the school, and the requirements of the national curriculum. The PD taken by a teacher needs to be approved by his/her reporting officers and must be relevant to the teacher's role and job scope. Schools have their own policies regarding what constitutes relevant training and their own approval process. The cost associated with PD is fully subsidized by MOE (Wang, Kim, Lee, \& Kim, 2014).

Findings from the 2013 Teaching and Learning International Survey (TALIS) conducted by the Organization for Economic Cooperation and Development (OECD, 2014) showed that participation rates in different types of PD activities are much 
higher in Singapore than in other countries. For example, considering the 34 nations that participated in the study, higher proportions of teachers at lower secondary levels participated in courses and workshops in Singapore (93\% of teachers as compared to the average of $71 \%)$, mentoring, peer observation, and coaching (65\% in Singapore as compared to $29 \%)$, seminars and conferences (61\% as compared to $44 \%)$, networked learning (53\% as compared to $37 \%$ ), and individual or collaborative school-based research ( $45 \%$ as compared to $31 \%)$.

PD in Singapore aims at providing teachers with learning opportunities targeted to meet their needs and responsive to their personal motivations and goals. To achieve such aims, the "Teacher Growth Model" (MOE, 2012) conceptualizes PD as a continuum that begins with initial preparation and induction, continual development and growth, and milestone programs for lifelong careers (Chong \& Fong, 2000). Thus, depending on the teachers' level of expertise (beginner, experienced, expert), they are commonly offered different PD "routes." Staff developers are appointed in many schools to facilitate the "match" between teachers" future career goals and the available learning opportunities, providing teachers with PD that is tailored to their competencies and interests, and moving them through the system (Hairon \& Dimmock, 2011). TALIS has also shown that Singapore schools have a very strong mentorship culture, having the highest proportion of teachers serving as mentors and role models for their younger peers $(39 \%$ of teachers as compared to the average of $14 \%$ ).

Another important strategy of the Singapore PD model is offering teachers three different tracks for their professional careers, which are called teaching track (with the highest level position being Principal Master Teacher), leadership track (whose highest role is Director-General of Education), and specialist track (whose highest role is Chief Specialist, in which teachers focus on research and teaching policy) (Tan, Wong, \& Goh, 2010). This strategy was developed to respond to teachers' professional goals and to foster talent and capacity in a systematic way.

\section{The Three Main Providers of Teacher PD in Singapore}

In Singapore, there are three main PD providers for primary and secondary teachers. One is the National Institute of Education (NIE), which is the main provider of courses and programs leading to higher qualifications in education for more junior teachers, in instructional leadership for senior teachers, and in education leadership for heads of department, vice-principals, and principals. The second provider is the Academy of Singapore Teachers (AST) and six Centers of Excellence, established by MOE in 2010, which bring together teachers from different schools to provide them with networked learning opportunities. The schools can be considered as the third major provider, as many PD opportunities are embedded in the workplace. Indeed, Singapore places much emphasis on collaborative and community-oriented forms of $\mathrm{PD}$, which are deemed to enhance not only teachers' content and pedagogical knowledge, but also to bring about a sense of belonging, camaraderie, and solidarity among teachers. 
The "Enhanced Partnership Model" stresses the strong tripartite relationship between these three PD providers, ensuring the coherence and rigor of the different opportunities offered to teachers in Singapore (NIE, 2009). Below we develop the approaches to PD adopted by these three providers and offer some illustrative examples.

\section{National Institute of Education (NIE)}

The National Institute of Education (NIE) is the sole institution that offers preservice teacher education programs in Singapore, and is one of the main PD providers for in-service teachers and other stakeholders (e.g., school senior management, curriculum specialist, teacher researchers). Since the 1970s, NIE has provided timely PD to Singapore's entire teaching force, in close coordination with MOE (Tan et al., 2010). For example, to address the shortage of teachers specialized in music and visual arts within Singapore primary schools, NIE has been offering an Advanced Diploma in Primary Music Education since 2011. NIE is committed to designing PD that meets the actual learning needs of the Singapore's teacher fraternity, equipping them with new competencies in response to today's societal requirements and demands.

NIE currently offers a wide variety of stand-alone short PD courses for inservice teachers from the different subject matters. Courses are primarily focused on subject content, curriculum development, pedagogies, assessment, and student learning. Most courses lead to the award of in-service diplomas and/or to advanced professional qualifications. For instance, the above-referred Advanced Diploma in Primary Music Education comprises 7 courses, which are divided into music content knowledge (music theory, World music), music skills (playing, conducting, performing), and curriculum studies (theory and practice in music education). This diploma enables primary music teachers to work towards other specialist diplomas, degrees, or higher degrees in teaching. In order to evaluate the impact of these kinds of programs, NIE often provides its faculty researchers with grants to evaluate changes in teachers' knowledge and classroom practices. For example, Costes-Onishi and her team are currently assessing the effectiveness of the Advanced Diploma in Primary Music Education (Costes-Onishi \& Caleon, 2014). In addition, as mentioned above, NIE is the main provider of graduate degree programs in education (e.g., Masters of Teaching, Masters of Education, $\mathrm{PhD}$ in Education), instructional leadership (e.g., Senior Teachers Program), and educational leadership (e.g., Management and Leadership in Schools). The MOE offers numerous scholarship opportunities for teachers who seek higher degrees in Singapore and overseas, either full-time or part-time ${ }^{2}$.

The delivery modes of NIE's PD courses and programs include specialists lectures and talks, hands-on workshops, project work, fieldwork, action research, and a wide range of academic activities that require both individual and group work. To

\footnotetext{
${ }^{2}$ Visit: http://www.nie.edu.sg/studynie/professional-development-programmes-and-courses/ 
complete the required coursework, teachers are generally requested to interact both face-to-face and online. Upon course or program completion, teachers are awarded either a certificate of attendance or a certificate of successful completion, depending on the specific requirements. In addition to attendance, PD that awards certificates of successful completion requires teachers to attain a minimum standard of performance.

NIE is involved in numerous small-scale school-university partnerships with primary and secondary schools interested in improving specific aspects of their curriculum and/or pedagogies (Wang et al., 2014). Moreover, NIE produces publications and other resources to further promote teachers' continuous learning. For example, summaries of the numerous research projects conducted by NIE faculty and research staff are periodically shared with the entire education community. The information publicized in the NIE's website makes special emphasis on the findings and implications of the studies, which are typically presented using an accessible language (e.g., avoiding technical jargon). The intent is to maximize the impact of research on teachers' knowledge and classroom practice. There are three other inhouse publications where NIE shares its research findings with local teachers and other stakeholders: 1) SingTeach, an electronic magazine targeted at practitioners, which publishes reports written by teachers; 2) NIE Research Brief Series, which is mainly targeted at policy-makers, school leaders, administrators, and researchers; and 3) ReED (Research in Education) bulletin, which is targeted at a more global educational community ${ }^{3}$.

\section{Academy of Singapore Teachers (AST) and six Centers of Excellence}

The second main PD provider is the Academy of Singapore Teachers (AST), which was established in 2010 along with six Centers of Excellence for teacher PD. The Academy brings together teachers from different schools and engages them in multiple types of networked learning. More specifically, the AST was designed to enable teachers to discuss and share innovative pedagogical practices in their specific subjects, thereby raising professional standards of disciplines and fostering a stronger teacher-led culture of professional exchange, collegial sharing, and collaboration (MOE, 2010).

The AST is continuing the cutting-edge work initiated in 1998 by MOE's Teachers Network, which first advocated the need for teacher-led, bottom-up PD initiatives (Hairon \& Dimmock, 2011). Following new trends identified in key innovative Anglo-Saxon schools, the Teachers Network designed and implemented a series of interrelated programs to facilitate teachers' collaboration, reflection, and inquiry (Tripp, 2004). The key learning platform was called "Learning Circles," where small groups of self-directed teachers engaged in activities such as action research or lesson study. Drawing on the knowledge built within these learning circles, teachers then engaged in other programs such as teacher-led workshops,

\footnotetext{
${ }^{3}$ Visit: http://www.nie.edu.sg/office-education-research/publications/
} 
conferences, website, and publications. The slogan "For Teachers, By Teachers" (MOE, 2005) accurately captures the philosophy of teacher learning and change supported by the Teachers Network. After 1998, subsequent educational policies and initiatives have continued to provide teachers with agency and responsibility regarding their career development. The rationale is that teachers should not be mere "recipients" or "implementers" of the ideas delivered in PD settings, but instead active "developers" of knowledge, assuming real ownership of their continuing learning (Ellis \& Armstrong, 2013; Hairon \& Dimmock, 2011; Wong, 2013). The Academy was created to build such fraternity of active, committed, and reflective teachers, and to spark the growth of learning communities amongst them.

The AST comprises four Subject Chapters (which can be thought of as disciplinary networked learning communities), each divided into concrete school subjects (Table 1). All MOE teachers who teach these subjects are invited to become members of the Subject Chapters, which provides them with numerous opportunities to learn with/from other fellow colleagues. According to the AST's website ${ }^{4}$, about 3,500 teachers took part in the activities organized through the Subject Chapters in 2014.

Table 1. Subject Chapters within the Academy of Singapore Teachers

\begin{tabular}{cccc}
\hline Humanities & Mathematics & Science & Others \\
\hline Geography & Primary Mathematics & Biology & Design \& Technology \\
History & Secondary Mathematics & Chemistry & Nutrition \& Food Science \\
Social Studies & & Physics & Principles of Accounts \\
& & Primary Science & \\
\hline
\end{tabular}

In addition to the Subject Chapters, there are six Centers of Excellence (also referred to as Academies or Institutes). Four offer PD to the teachers of the different languages taught in Singapore schools, namely English, which is the main medium of instruction (English Language Institute of Singapore), Mandarin (Singapore Center for Chinese Language), Malay (Malay Language Center of Singapore), and Tamil (Umar Pulavar Tamil Language Center). The other two centers specialize in the PD of Music and Arts teachers (Singapore Teachers' Academy for the Arts) and Physical Education teachers (Physical Education \& Sports Teacher Academy).

The Subject Chapters and the Centers of Excellence organize a wide variety of PD initiatives for teachers, ranging from formal activities (e.g., workshops on schoolbased research methods, courses and seminars focused on content knowledge and pedagogical content knowledge, conferences, symposiums) to more reform-type PD activities (e.g., action research, collaborative reflective discussions). Teachers' learning is supported by "One Portal All Learners" (OPAL), an online platform with several content management repositories containing useful information and learning materials.

\footnotetext{
${ }^{4}$ Visit: http://www.academyofsingaporeteachers.MOE.gov.sg/ 
Let's see some examples of PD activities recently conducted by the AST. A series of workshops on lesson study provides an example of formal PD. Targeted at primary, secondary, and junior college science teachers, the workshops were developed to support teachers' discourse and reflection within their respective schools (Heong, 2012). Another example is the "Structured Mentoring Program", in which beginning teachers receive support and guidance from more senior colleagues during their induction to the teaching profession (Wong, 2013).

Regarding reform-type PD, the "Teacher-Researcher Networks" is one of the most interesting initiatives. Teacher-Researcher Networks are learning communities composed of faculty researchers from NIE, senior specialists from MOE, and teacherresearchers, including those with higher formal training in research (who are called "research activists"). The overall goal of these learning communities is to provide teachers with resources to engage in action research (Hairon, 2006), a form of classroom-based investigation where teachers discuss and reflect upon pedagogical problems and find their own solutions to improve teaching and learning. Action research requires teachers to systematically observe teaching and learning situations and collect empirical evidence, which can be used later on by the practitionerresearcher in reflection, decision-making, and the development of more effective pedagogies. Action research cycles typically follow the structure of a problemsolving procedure, which includes five steps:

1. Identification and definition of a problem;

2. Planning for improvement;

3. Implementation of teaching/learning activities;

4. Observation of results (data collection);

5. Reflection on the outcomes.

When the action research cycle is completed, participants write a group reflective journal to summarize the procedures, findings, conclusions, and implications of the study. Action research journals are typically used as resources to be shared with other groups of teachers interested in similar classroom problems. The AST provides teachers with forums to share their research findings, including an annual symposium and publications (Ellis, 2014). The action research process and the collaboration with the different members of the teacher-researchers network typically help teachers to increase their competencies for reflection and inquiry. With the support of school senior management, these PD experiences have the potential to empower teachers to initiate school-based curricular development and innovation.

\section{School-based PD: Professional Learning Communities (PLCS)}

Much of the professional development of Singaporean primary and secondary teachers occurs within school settings, where they have numerous work-embedded learning opportunities. In fact, it is understood that schools should be the main organizations that promote teacher learning, and that schools themselves should be conceived of as "learning organizations." In 2009/10, after more than a decade of innovative PD initiatives, the MOE mandated all public schools to become Professional Learning Communities (PLC). This policy (see MOE, 2010) made 
Singapore the first country in the world to adopt the PLC framework nation-wide (Dimmock \& Tan, 2013; Hairon \& Dimmock, 2011).

Led by school leaders (e.g., staff developers, heads of departments, content specialists), and always with the support of the Academies, PLC provide teachers with structures and resources to engage in a variety of inquiry-based PD practices such as action research, lesson study, and a wide range of learning circles focused on different topics (e.g., curriculum innovation, student-centric teaching practices, new uses of ICT, collaborative lesson planning, and project-based learning). Groups of colleagues who learn together and collaborate are referred to as "Learning Teams." These typically complete their work during protected time slots called "white spaces" (Wong, 2013). MOE schools are encouraged to provide at least one hour of curricular time per week for teachers to actively engage in these kinds of school-based PD initiatives. The learning teams commonly plan for about 8-10 two-hour sessions spread over the entire academic year. These hours of work are acknowledged in teachers' appraisal, contributing to the annual 100 hours of optional training entitlement.

One of the most widespread practices within PLCs in Singapore is action research (Hairon, 2006; Wong, 2013), which was described above. Another form of school-based PD that has gained momentum is Japanese lesson study (Lewis, Perry, \& Hurd, 2004), which was introduced in Singapore schools in 2005. Similar to action research, the overall goal of lesson study is to foster collaborative inquiry and datadriven pedagogical reflection amongst teachers. Despite the multiple variations of this approach in the literature, Singapore teachers generally adopt standard models consisting of four cyclical and recursive phases (Tan, 2014):

1. Study phase, when teachers analyze the curriculum to be taught and formulate long-term teaching and learning goals;

2. Planning phase, when teachers select research lessons, predict student thinking and difficulties, and plan the implementation of specific lessons for data collection;

3. Analysis phase, when teachers observe and discuss the classroom evidence collected (e.g., videos, student written work);

4. Reflection phase, when teachers discuss student learning and identify new areas for further inquiry.

MOE has consistently made great efforts to support the success of the PLC initiative. For example, MOE produced a handbook (called "PLC Starter Kit") explaining the benefits of PLCs, the roles played by the different members, and the methods, procedures, and tools that can be used when conducting classroom-based research (TDD, 2010). Moreover, MOE provides funds to train a few teachers within each school to become "research activists," with the expectation being that they will help their peers later on in conducting classroom-based research ${ }^{5}$ (Ellis, 2014). They

\footnotetext{
${ }^{5}$ In addition to the action-research conducted by teachers internally at schools, there are some NIE researchers who also conduct independent research on the topic (see Hairon, 2006; Tan, 2014). 
are also expected to spend part of their time conducting development work, proposing curriculum innovations, and carrying out cutting-edge classroom-based research with potential implications for educational policy and teaching practices. A pilot of the PLC initiative was conducted in 2009 with 51 schools. By 2013, practically all MOE schools in the country were already on board in this scheme (Lee, Hong, Tay, \& Lee, 2013).

\section{Future Directions}

It is obvious that measuring the impact of such a comprehensive PD model is a rather difficult enterprise. As explained above, teachers in Singapore "craft" their own PD routes in consultation with school leaders. Thus, given the variety and diversity of activities in which they can potentially participate every year, conducting large-scale quantitative studies to measure the effectiveness of PD in Singapore would be highly complicated, as the number of uncontrolled and confounding variables would be high. Yet, despite methodological difficulties, we suggest that more research should be conducted to investigate the extent to which such an ambitious PD model is enhancing teachers' knowledge and pedagogies, and ultimately students' learning. International PD researchers have recently proposed new research methodologies, both quantitative (Hill, Beisiegel, \& Jacob, 2013) and qualitative (Kazemi \& Hubbard, 2008), that could be applied in the Singapore context.

Some studies conducted by NIE researchers have investigated the effectiveness of specific formal PD courses/programs and other school-university collaborative projects in mathematics (Kaur, 2011), science (Tan \& Nashon, 2013), arts and music (Costes-Onishi \& Caleon, 2014), and assessment literacy practices (Koh, 2011). Most published research is qualitative and based on small numbers of participants. Studies have primarily focused on teachers' learning (changes in their beliefs, knowledge, skills, and to a lesser extent, classroom practices) but seldom on students' learning. Overall, the PD experiences described in these studies yielded positive results, ranging from modest to significant improvements. In contrast, there is not much published research on the effectiveness of informal (work-embedded, teacher-led) forms of PD such as action research or lesson study, despite being very widespread in Singapore. Action research and lesson study are commonly said to help teachers in developing sophisticated research skills (Wong, 2013). However, given that these forms of PD require enormous resources in terms of time and effort on teachers' end, we think that having empirical evidence of their actual impact on teachers' pedagogies and student's learning should be of high priority for PD researchers.

A recent survey study conducted by Lim, Lee, Saito, and Syed Haron (2011) has shown that Singapore teachers are generally positive about lesson study, as they believe it gives them the chance to learn from their fellow colleagues and grow professionally. Study participants considered this PD approach had a positive impact on their teaching strategies and helped them gain a better understanding of their students. Lim et al. (2011) also found that teachers who actually taught a research lesson were more supportive of lesson study. This research revealed a series of factors that are essential for the success of lesson study, such as having the support 
from school leaders and teachers' own conviction about the effectiveness of this approach, the provision of protected time in teachers' weekly schedules, and the presence of a lesson study advocator within the working group.

\section{Challenges}

Despite all the resources in place to support the professional development of teachers in Singapore, there are also challenges and constraints important to consider. One of them has to do with accessibility. For example, teachers from some primary schools are often only allowed to attend PD that is related to the subject matters in which they specialize (e.g., mathematics), even though most of them teach a myriad of other subjects (e.g., music, arts). This results in lost opportunities to improve their teaching competences in areas that are out of their specialization (Wong \& Bautista, submitted). A second challenge has to do with teachers' overwhelming amount of work (Hairon \& Dimmock, 2012), including high teaching loads, various academic responsibilities (e.g., marking, meeting with parents), and administrative duties (e.g., sitting in committees). Having to fulfill all these responsibilities makes it harder for teachers to bring all their energy, commitment, and enthusiasm into the PD activities in which they participate.

Another challenge is related to high stakes examinations. The Singapore education system is highly competitive and selective (Hogan \& Gopinathan, 2008). Obtaining good grades is essential for students to ensure their professional future. Similar to other Asian countries, being successful academically is highly regarded and rewarded by families and society as a whole. In addition, students' test scores are one of the factors considered when appraising teachers' performance. For all these reasons, many educators in Singapore feel the need to "teach to the test" and "drill students" with lectures and reproductive learning activities, thus leaving behind what they learn in PD settings (e.g., innovative teaching approaches, student-centric pedagogies, inquiry-based learning activities). Moreover, teachers oftentimes face immense pressures from parents to resort to rote teaching in order to ensure their children achieve good grades in exams. For example, some Singapore parents complain when the amount of homework assigned by a teacher is low, requesting more and more worksheets for their children to complete at home. These types of parental pressures are also powerful enough to constrain the impact of PD in actual classroom practices, much to the frustration of teachers and school leaders (Berthelsen, Brownlee, \& Karuppiah, 2011).

\section{Summary and Conclusions}

Teaching has to become, first and foremost, a learning profession; teachers will have to learn to learn in different ways, and reconstruct themselves as advanced specialist practitioners of learning with their pupils as their apprentices (Tripp, 2002, p. 4) 
In this paper, we have mapped the landscape of the PD opportunities offered to Singapore teachers from MOE primary and secondary schools. We have seen that teachers' PD entitlement is extraordinarily high (up to 100 hours per year), and that there is a wide variety of PD activities teachers can engage in, ranging from formal and structured forms of PD (offered primarily by the NIE, and to a lesser extent, by the Academies) to more informal reform-type forms of PD (conducted at the Academies and also embedded in the everyday work of schools). Current policy initiatives such as the "Teacher Growth Model" (2012) argue in favor of PD that is coherent with and responsive to teachers' needs and interests. For example, teachers with different levels of expertise (beginner, experienced, expert) and desired career paths (teaching, leadership, specialist tracks) are typically offered different PD opportunities. Much of the PD is subject-specific (e.g., mathematics, science, music) and provides teachers with opportunities for network learning, collegial sharing, and collaboration. In fact, all Singapore schools have been recently mandated to adopt the PLC framework, in order to promote high levels of collective participation amongst teachers and leaders within the same institution.

We conclude that this extensive set of PD resources, considered as a whole, presents the features of "high-quality" PD described in the international literature (Avalos, 2011; Bautista et al., 2015; Borko, 2004; Darling-Hammond \& McLaughlin, 2011; Desimone, 2009). In particular, the current teacher PD model in Singapore is: (a) subject-matter specific and connected to classroom practice; (b) intensive and ongoing; (c) provides teachers with opportunities for active learning; (d) promotes collective participation amongst teachers both across and within schools; and (e) is coherent with teachers' needs and interests, and aligned with school and national priorities and goals. Despite presenting all these positive features, however, we have suggested that more systematic research should be conducted to investigate the extent to which this comprehensive and ambitious PD model is helping teachers in further enhancing their knowledge and pedagogies, and ultimately in improving students' learning (Hill et al., 2013).

As explained in the Introduction, we are aware that the success of the Singaporean education system cannot be explained exclusively by the quality and quantity of the PD offered to its teaching force, as there are many other macro, organizational, and family-level factors that are important in this equation (Dimmock \& Tan, 2013; Hairon \& Dimmock, 2011; C. Y. Tan \& Dimmock, 2014). With this caveat in mind, this paper shows that the Singapore system as a whole has responded very well to the challenges of curricular and pedagogic reform. Resources have been more than adequate and the variety of PD opportunities has become a norm. MOE's generous leave and sponsorship schemes have led to more teachers engaging in PD activities (including post-graduate programs), thus deepening their knowledge and expertise. There has been a clear recognition that capacity building is essential, that teaching should be seen and practiced as a reflective profession, and that teachers should take ownership of their own professional growth (Deng et al., 2013). We invite the readers of Psychology, Society and Education to consider how the ideas 
presented in this paper could be used to improve the teacher PD models in their own countries.

\section{References}

Avalos, B. (2011). Teacher professional development in teaching and teacher education over ten years. Teaching and Teacher Education, 27(1), 10-20.

Bautista, A., Cañadas, M. C., Brizuela, M. B., \& Schliemann, A. D. (2015). Examining how teachers use graphs to teach mathematics in a professional development program. Journal of Education and Training Studies, 3(2), 91-106. http://redfame.com/journal/index.php/jets/article/view/676/624

Bautista, A., Ortega-Ruíz, R. (2015). Teacher professional development: International perspectives and approaches. Psychology, Society and Education, 7(3), 240-251.

Berthelsen, D., Brownlee, J., \& Karuppiah, N. (2011). Teaching beliefs and practices in early childhood education in Singapore Singapore: Pearson Education.

Borko, H. (2004). Professional development and teacher learning: Mapping the terrain. Educational Researcher, 33(8), 3-15.

Chong, T. H., \& Fong, H. K. (2000). Pre-service preparation and professional development of mathematics teachers in Singapore. The Mathematics Educator, 5(1/2), 83-90.

Costes-Onishi, P., \& Caleon, I. (2014). Generalists to specialists: Transformative evidences on the practices of music and art teachers in Singapore. Paper presented at the AARE-NZARE International Conference, Brisbane, Australia.

Darling-Hammond, L. (2010). Teaching for deeper learning: Developing a thinking pedagogy In A. P. C. Avila, C. Hui, J. H. Lin, J. C. Peng Tam \& J. C. Lim (Eds.), Rethinking Educational Paradigms: Moving from Good to Great. CJ Koh Professorial Lecture Series No. 5 (pp. 13-18). Singapore: Office of Education Research, National Institute of Education.

Darling-Hammond, L., \& McLaughlin, M. W. (2011). Policies that support professional development in an era of reform. Phi Delta Kappan, 92(6), 81-95.

Deng, Z., Gopinathan, S., \& Lee, C. K.-E. (2013). Globalization and the Singapore curriculum: From policy to classroom. Singapore: Springer.

Desimone, L. M. (2009). Improving impact studies of teachers' professional development: Toward better conceptualizations and measures. Educational Researcher, 38(3), 181199.

Dimmock, C., \& Tan, C. Y. (2013). Educational leadership in Singapore. Journal of Educational Administration, 51(3), 320-340. doi: http://dx.doi.org/10.1108/09578231311311492

Ellis, N. J. (2014). Afraid to lose out: the impact of kiasuism on practitioner research in Singapore schools. Educational Action Research, 22(2), 235-250. doi: $10.1080 / 09650792.2013 .859088$

Ellis, N. J., \& Armstrong, A. C. (2013). How context shapes practitioner research and professional learning in schools in Singapore and NSW. Compare: A Journal of Comparative and International Education, 44(3), 435-454. doi: $10.1080 / 03057925.2013 .767674$

Goh, C. T. (1997). Speech by Prime Minister Goh Chok Tong at the opening of the 7th International Conference on Thinking", Monday, June 2, 1997, at 9.00 am at the Suntec City Convention Centre Ballroom. Available at http://www.moe.gov.sg/media/speeches/1997/020697.htm. 
Gopinathan, S. (2012). Fourth way in action? The evolution of Singapore's education system. Educational Research for Policy and Practice, 11(1), 65-70. doi: http://dx.doi.org/10.1007/s10671-011-9117-6

Hairon, S. (2006). Action research in Singapore education: constraints and sustainability. Educational Action Research, 14(4), 513-523. doi: 10.1080/09650790600975684

Hairon, S., \& Dimmock, C. (2011). Singapore schools and professional learning communities: teacher professional development and school leadership in an Asian hierarchical system. Educational REview, 64(4), 405-424. doi: $10.1080 / 00131911.2011 .625111$

Heong, Y. L. (2012). Lesson study as professional development of science teachers in professional learning community schools. SCIOS, 48(1), 4.

Hill, H. C., Beisiegel, M., \& Jacob, R. (2013). Professional development research: Consensus, crossroads, and challenges. Educational Researcher, 42(9), 476-487.

Hogan, D., \& Gopinathan, S. (2008). Knowledge management, sustainable innovation, and preservice teacher education in Singapore. Teachers \& Teaching, 14(4), 369-384.

Kaur, B. (2011). Enhancing the pedagogy of mathematics teachers (EPMT) project: a hybrid model of professional development. ZDM, 43(6-7), 791-803. doi: 10.1007/s11858-011-0364-z

Kazemi, E., \& Hubbard, A. (2008). New directions for the design and study of professional development: Attending to the coevolution of teachers' participation across contexts. Journal of Teacher Education, 59(5), 428-441.

Koh, K. H. (2011). Improving teachers' assessment literacy through professional development. Teaching Education 22(3), 255-276.

Lee, D., Hong, H., Tay, W., \& Lee, W. O. (2013). Singapore Professional Learning Communities in Singapore Schools. UK Society for Co-operative Studies, 46(2), 5356.

Lewis, C., Perry, R., \& Hurd, J. (2004). A deeper look at lesson study. Educational Leadership, 61(5), 18-23.

Lim, C., Lee, C., Saito, E., \& Syed Haron, S. (2011). Taking stock of Lesson Study as a platform for teacher development in Singapore. Asia-Pacific Journal of Teacher Education, 39(4), 353-365. doi: 10.1080/1359866X.2011.614683

Ministry of Education (MOE). (2005a). Speech by Mr Tharman Shanmugaratnam, Minister for Education, at the MOE Work Plan Seminar 2004, Ngee Ann Polytechnic Convention Centre, Thursday 22 September, 10:00 a.m. http://www.moe.gov.sg/media/speeches/2005/sp20050922.htm

Ministry of Education (MOE). (2005b). Teach Less, Learn More. Singapore Education Milestones 2004-2005. Singapore: Retrieved from http://moeedu.sg/about/yearbooks/2005/teach.html.

Ministry of Education (MOE). (2010). Schools as professional learning communities. Singapore: Author.

Ministry of Education (MOE). (2012). The Teacher Growth Model. Singapore: Retreived from http://www.moe.gov.sg/media/press/files/2012/05/fact-sheet-teacher-growthmodel.pdf.

National Institute of Education (NIE). (2009). A Teacher Education Model for the 21st Century. Singapore: NIE.

OECD. (2014). A Teachers' Guide to TALIS 2013: Teaching and Learning International Survey. Paris: TALIS, OECD Publishing. 
Schwab, K. (2015). World Economic Forum's Global Competitiveness Report, 2014-2015. Retrived from: http://reports.weforum.org/global-competitiveness-report-20142015/. Switzerland: World Economic Forum.

Tan, C. Y., \& Dimmock, C. (2014). How a 'top-performing'Asian school system formulates and implements policy: the case of Singapore. Educational Management Administration \& Leadership, 1741143213510507.

Tan, I., Wong, I., \& Goh, C. (2010). Strategic teacher professional development. In A. Y. Chen \& S. L. Koay (Eds.), Transforming Teaching, Inspiring Learning. 60 years of teacher education in Singapore (1950-2010) (pp. 147-158). Singapore: NIE/NTU.

Tan, Y., \& Nashon, S. (2013). Promoting Teacher Learning Through Learning Study Discourse: The Case of Science Teachers in Singapore. Journal of Science Teacher Education, 24(5), 859-877. doi: 10.1007/s10972-013-9340-5

Tan, Y. M. (2014). Enriching a collaborative teacher inquiry discourse: exploring teachers' experiences of a theory-framed discourse in a Singapore case of lesson study. Educational Action Research, 22(3), 411-427. doi: 10.1080/09650792.2014.880360

Training and Development Division (TDD). (2010). Schools as professional learning communities. Singapore: Training and Development Division, Ministry of Education.

Tripp, D. (2002). Valuing the teaching profession: purpose, passion and hope. Response to Margot Cameron-Jones' and Belinda Charles' plenary papers presented at the Singapore National Institute of Education Symposium. Openning of Nanyang Campus, 25 January. Available on VCD from NIE (Singapore).

Tripp, D. (2004). Teachers' networks: A new approach to the professional development of teachers in Singapore. In C. Day \& J. Sachs (Eds.), International handbook on the continuing professional development of teachers (pp. 191-214). Maidenhead England: Open University Press.

Wang, X., Kim, B., Lee, J. W. Y., \& Kim, M. S. (2014). Encouraging and being encouraged: Development of an epistemic community and teacher professional growth in a Singapore classroom. Teaching and Teacher Education, 44, 12-24. doi: http://dx.doi.org/10.1016/j.tate.2014.07.009

Wong, K. Y. (2013). Diverse pathways for life-long teacher professional development. Paper presented at the International Science, Mathematics and Technology Education Conference (ISMTEC 2013), Bangkok, Thailand.

Wong, J., \& Bautista, A. (submitted). Features of most and least helpful professional development experiences: A study with primary music specialists. Paper presentation. Annual Meeting of AERA, Public Scholarship to Educate Diverse Democracies. Washington, DC (April, 2016). United States. 